A practical test was carried out for six months at thirty collieries in Scotland, and 96.3 per cent. of eye injuries were treated with no loss of working time.

In the hospital treatment of the developed hypopyon ulcer the method of application of Albucid Soluble is still in the experimental stage, but the results appear to be satisfactory.

Acknowledgments.- We have pleasure in making the following acknowledgments. The bacteriology of the Edinburgh cases was done by Dr. A. J. Rhodes, and of the Glasgow cases by Dr. W. B. Kyles. We are indebted to Professor T. J. Mackie of Edinburgh University for his interest and guidance in this part of the work.

Dr. J. M. Robson and Major G. I. Scott conducted the research on Albucid Soluble at the Pharmacology Department, Edinburgh University.

We have to thank Dr. H. M. Traquair and Dr. E. H. Cameron of the Royal Infirmary, Edinburgh, and Dr. S. S. Meighan and Dr. John Marshall of Glasgow Eye Infirmary for their courtesy in making available all clinical material in their eye wards.

Our thanks are also due to Dr. P. L. McKinlay of the Department of Health for Scotland for his valuable help in the statistical work.

\title{
REFERENCES
}

1. RHODES, A. J.-Brit.Jl. Ophthal., Vol. XXIII, p. 25 and p. 627.

2. Robson, J. M. and Scott, G. I.-Nature, Vol. CXLVIII, p. 167, 1941, and Vol. CXLIX, p. 581, 1942; Brit. Med. Jl., January 3, 1942.

RoBson, J. M. and TEBRICH, W.-Nature, Vol. CXIVIII, p. 695, 1941 ; Brit. Med. Jl.. June 6, 1942.

3. ScorT, G. I.- "The value of sulphonamides in ophthalmology." Paper read at the meeting of the Ophthalmological Society of the United Kingdom.

\section{SYMPATHETIC OPHTHALMITIS}

BY

\section{T. HARRison ButLER}

Sympathetic ophthalmitis is a rare disease, and some surgeons have never seen a case. Professor Franschetti told me some twelve years ago that he had never seen one in Professor Vogt's Clinic at Zürich. During thirty years' work at the Coventry Hospital I had two cases both of which might have been prevented. One was a man whose eye was perforated by a piece of coal. I failed to remove this from the interior of the eye, and eventually advised that the eye should be excised. My advice was disregarded and sympathetic ophthalmitis developed. The injured eye was removed 
and a course of mercurial inunction carried out for a long time. Eventually at the end of nine months the eye made a complete recovery. This was some 28 years ago, before thẹ age of treatment with massive doses of salicylates and later with N.A.B.

The second case was a woman who refused enucleation after an unsuccessful cataract extraction. Sympáthetic inflammation set in, and when the patient was seen it had been active for a fortnight. Nothing could be done to save the eye. The clinic at Coventry is a busy one; a large number of serious accidents are treated, and about 200 major operations performed every year. Under these conditions the occurrence of only two examples in 30 years proves the rarity of the disease.

During 20 years at the Warneford Hospital, Leamington, I saw only one case of the sympathetic type. This was a boy of 10 or so who had a small perforation in the limbal region. Some time after the accident the anterior chamber on each side was found to be full of particles shewing well-marked convection currents. These rapidly increased in number till in each anterior chamber a ring rather like a vortex.ring of smoke was present. In the beam of the slit-lamp this could be seen easily with an ordinary loupe magnifying six times. I have never before or since seen such an astonishing mass of particles in the anterior chamber. This boy made a rapid and complete recovery with injections of N.A.B. There was never any "K.P." and the presence of particles was the sole reason for diagnosing the case as one of sympathetic ophthalmitis.

During 18 years at the Birmingham Eye Hospital I saw several cases. In a large Eye Hospital the cases do not get the individual expert supervision from, the Honorary Surgeon that they obtain in the Eye Department of a General Hospital. The old cases and the operation cases are seen by the House Surgeons who have neither knowledge nor the experience necessary to diagnose sympathetic ophthalmitis in its earliest stages. As sympathetic ophthalmitis has never been indexed I cannot trace my cases, but I can say from memory that every example that was recognised early and treated with N.A.B. made a good recovery. In all about two or three were lost, but most of these occurred before the value of N.A.B. both as a prophylactic and for treatment had been discovered.

- During the past ten years I have not had any sympathetic ophthalmitis atthough during this period I have been most conservative in my treatment of eyes that have suffered from accidents or have given anxiety after operation.

In spite of all the research that has been carried out, and the theories that have been formed, I think that I shall not be seriously criticised when I say that we know literally' nothing about the 
ultimate cause of the disease. We know that sympathetic ophthalmitis follows the puncture of the exciting eye, and that apart from inflammations associated with the presence of sarcomata in the exciting eye, it occurs under no other conditions. In my opinion the exception can be discounted. I do not believe that the serious plastic iridocyclitis that can be caused by a sarcoma in the other eye is the same disease as sympathetic ophthalmitis. It differs in one important particular. When the eye containing the sarcoma is remored, the sympathising eye can make a complete recovery. I believe that sympathetic ophthalmitis does not exist apart from a punctured globe. Before we can make a diagnosis we must satisfy ourselves that an irido-cyclitis is present in the punctured globe, and that there is no other extraneous cause for the inflammation in the sympathising eye. We know that sympathetic ophthalmitis rarely begins. within a fortnight of the accident, and that the remaining eye can be considered safe a month after the removal of the injured eye. I believe that those cases which have been reported as occurring long periods after the removal of a punctured eye are examples of $a$ chronic smouldering sympathetic ophthalmitis that have never been properly examined with the slit-lamp, and have never been recognised as examples of sympathetic ophthalmitis. The case of Minda H.; which I shall describe to you, is a case of this nature. I have seen three cases in which sympathetic ophthalmitis began exactly 14 days after excision of the damaged globe, and I wonder whether the removal of the eye may have produced conditions favourable for the development of sympathetic ophthalmitis. I am here purposely vague in my phraseology.

Sympathetic ophthalmitis has a pathology of its own which was described by Fuchs, but it is so like a tuberculous process that Professor Meller in his Doyne Memorial Lecture for 1934 told his audience that he had proved to his own satisfaction that sympathetic ophthalmitis was a tuberculous state. Probably few will agree with him.

From what has been said it is obvious that the diagnosis of sympathetic ophthalmitis is not an easy one, at any rate in the majority of cases. It is a good rule to realise that rare diseases really are rare, and that the case under consideration is in all probability not suffering from sympathetic ophthalmitis. The fact that an operation has been performed upon an eye does not confer upon it or its fellow any immunity from ordinary iridocyclitis which is often bilateral. The very fact that an operation has been performed may precipitate an attack of iridocyclitis although we may have no idea as to how or why. I have occasionally seen binocular iritis after an operation, and more rarely bilateral iridocyclitis. These two conditions may be pathologically allied, but 
clinically they seem to me to be quite different. The correct diagnosis depends upon a careful examination of both eyes and of the general condition of the patient. As Schirmer has pointed out, we are not warranted in diagnosing sympathetic ophthalmitis till we have satisfied ourselves that there is no other cause for the inflanimation.

The slit-lamp is a most important instrument in the differential diagnosis. The presence of particles in the anterior chamber and the determination of the rapidity of their movements is most important in the case of the exciting eye, and of vital import in the sympathising eye. Not less valuable is the presence of particles in the retro-lental space, and of exudative foci in the vitreous. Fine " K.P." of the pellucid type may be detected with the slitlamp when it is difficult to see with the loupe alone. The presence of pigmented particles does not worry me. They generally come from the surface of the iris, and in the aged have little significance. The detection of any of these anomalies in the sympathising eye is serious and makes the diagnosis of sympathetic ophthalmitis probable. For this reason it is essential to make frequent and careful examination with the slit-lamp of any eye that is under suspicion. If we wait till we obtain the "classical signs" of sympathetic ophthalmitis, the copious mutton fat "K.P.", the plastic exudates, and synechiae, we have probably lost our chance of saving the eye.

Prophylaxis is the best treatment. If an eye has been wounded so severely that it has lost its value as an organ of sight it ought to be removed. Short of this the greatest experience is called for to decide whether an injured eye should be saved or not. In all cases our bias ought to be towards saving the organ. As we have seen, sympathetic ophthalmitis' is a rare disease and the chance that any given accident will cause it is really minimal. Only when an injured eye begins to show signs of iridocyclitis will the question of excision be considered, and the result of treatment will have much to do with our procedure. Naturally if the eye contains a foreign body an attempt will be made to remove it. I am convinced that a full course of N.A.B. is valuable not only as direct treatment of the iridocyclitis, but as a prophylaxis against sympathetic ophthalmitis. So much so that for the past five years I have given up injections of activated sera and boiled milk.

Can we get any help from a blood count? After having scores of blood counts made in many cases of severe injury during a period of 25 years, I have no hesitation in saying that they have no value whatsoever. I have found a normal differential blood count in practically every case of sympathetic ophthalmitis that I have seen. The one exception was the case that I lost at Coventry. A normal blood count gives me no comfort and an abnormal one does not worry me. If in spite of treatment the iridocyclitis does not 
improve, if the eye gets tender and soft, then I should remove the eye. I agree with Mr. J. Jameson Evans, that it is more dangerous to temporise in the case of a child than of an adult. If sympathetic ophthalmitis has developed then I should be still more hesitant about removing the exciting eye, and should do so only were I quite certain that it had little or no prospect of retaining any useful vision. In the majority of cases the sympathetic inflammation is more severe and devastating than that in the exciting eye, and when once it has got a hold the prospects of the wounded eye are better than those of the sympathising. This was not always my opinion, but I was completely converted by the arguments put forward by Malcolm Hepburn and S. H. Browning at a discussion on sympathetic ophthalmitis at the Oxford Congress, in 1926.

Theibest treatment of sympathetic ophthalmitis is, as I have-said, prophylaxis. When the disease has actually developed there would seem to be but one line of treatment, to push N.A.B. to the limit of safety, and use atropine locally. It is doubtful whether salicyclic acid has any real value, and I have not used it for a long time.

The results of treatment are very gratifying. In a paper that I read to the Oxford Congress in 1928 (Trans. Ophthal. Soc. U.K., Vol. XLVIII, page 346), I summarised the notes of ten cases of sympathetic ophthalmitis. Two of them went completely blind. The other eight made a complete recovery. All depends upon early diagnosis, and immediate treatment with N.A.B., I regard this drug as specific for sympathetic ophthalmitis, and much credit is due to Browning for his enthusiastic recommendation of this line of treatment. Occasionally one sees a report of a case of sympathetic ophthalmitis which has commenced several months after the original accident, or at an unusually long time after the removal of the offending eye. I am inclined to think that such cases, if they indeed be real examples of it, are aggravations of a slight attack of sympathetic ophthalmitis which has been overlooked. Such a case has been under my charge for the past 13 years. She came to the Birmingham Eye Hospital in 1925, at the age of 8 years. There was at the limbus of the left cornea a small cystic iris prolapse. The mother thought that the end of her brother's whip had caught the eye. A mistaken attempt was made to free the iris, and a fortnight later " K.P." was detected in the injured eye, and a day later the right anterior chamber was full of floating cells, with films and fibres of fibrin. The left eye was removed and the anterior chamber became normal, all the particles and debris disappearing. But from that time to now there have always been a few spots of small pellucid "K.P." They are not the same spots. They absorb and others take their place. Apart from this the eye is normal with full vision, and no evidence of 
any inflammation. But the eye is not normal; it is in my opinion suffering from chronic sympathetic ophthalmitis, and it is possible that there might be a flare up with serious consequances. The excised eye was examined by Mr. Treacher Collins, and he reported that it showed the typical Fuchs choroiditis, and that it was in his opinion a dangerous eye. It is possible that had I retained the eye it would have made a complete recovery, and that the girl would have two useful eyes instead of one. A case almost exactly the same seen two years later at Leamington, was treated with N.A.B. The injured eye was not removed, and both made a complete recovery as far as I know. This case was last examined in June, 1942. A little fine pellucid "K.P." was still present, but the eye was otherwise normal.

\title{
A CHOROIDAL MELANOMA TREATED BY SURGICAL DIATHERMY
}

BY

\author{
- L. H. Savin and G. C. Pritchard \\ LONDON,
}

THE following case raises interesting questions for discussion :-

On December 3, 1941, L.U,, an R.A.F. corporal, aged 37 years, attended medical outpatients at King's College Hospital, complaining of severe headaches, which frequently incapacitated him. He was seen by Dr. Brigden, who found no general or local cause for the pain. His Wassermann reaction was negative. He was referred to the eye department. Here he was carefully refracted and pronounced emmetropic. Vision was $6 / 5$ in each eye. Fields were normal and there were no abnormal scotomata. His eyes were normal except for a small choroidal melanoma of the left eye (Fig. 1). The melanoma extended above to a branch of the central vein; its lower pole just touched a branch of the artery. Provisionally the tumour was diagnosed " choroidal mole "; but the patient was kept under observation. Three weeks later the lower pole of the tumour was found to extend to the other side of this branch of the artery-the growth was extending slightly, and appeared to be one of the rare cases of a malignant melanoma developing from a benign pre-existing melanoma (Grinker, 1940).

Choice of treatment was difficult. Our first impulse to enucleate the eye was restrained by the unexplained headaches, which we thought might indicate secondaries, and the good vision in the eye $(6 / 5)$. As the growth was small we decided to destroy it by surgical diathermy. The position of the growth was carefully localised ophthalmoscopically. 